Молочная продуктивность

\title{
О МЕХАНИЗМЕ МОЛОКООТДАЧИ У КОРОВ ПРИ ПОВЫШЕНИИ РАЗОВОГО УДОЯ
}

\section{В.П. МЕЩЕРЯКОВ $\bowtie$}

Регуляция интенсивности перемещения молока по системе протоков молочной железы у коров осуществляется посредством изменения тонуса симпатической нервной системы. При этом характер сократительной реакции альвеолярного комплекса при накоплении в вымени разного количества молока в настоящее время не изучен. В представленной работе впервые установлено, что выведение повышенного количества молока сопровождается изменением показателей кровоснабжения вымени, вызванным повышением сократительной реакции альвеолярного комплекса. Нашей целью была оценка механизма сократительной реакции альвеолярного комплекса и молоковыведения у коров при повышении величины разового удоя. Исследование проводили во Всероссийском НИИ физиологии, биохимии и питания сельскохозяйственных животных (Калужская обл.) на 9 коровах (Bos taurus taurus) черно-пестрой породы 2-5-го отелов в первую половину лактации методом периодов. На каждой корове в контроле и опыте было проведено по 7 наблюдений. В контрольный период разовый удой коров колебался от 3,4 до 6,7 кг, в опытный его величина превышала контроль на $24,5 \%$ (р < 0,001). Доение осуществляли серийным доильным аппаратом АДУ-1, параметры молоковыведения регистрировали с помощью ковшового счетчика-датчика (Латвия). Объемную скорость кровотока (ОСК) в вымени оценивали методом электромагнитной флоуметрии. Датчик кровотока («Nihon Kohden», Япония) накладывали на наружную срамную артерию вымени. До начала доения в течение 3 мин регистрировали средние значения ОСК (исходный период), затем регистрировали ОСК на протяжении доения. На кривой ОСК отмечали точки, характеризующие изменение кровоснабжения вымени: начала раздражения молочной железы, моментов резкого увеличения кровоснабжения и достижения его максимума, а также возвращения значений ОСК к исходным показателям. Рассчитывали длительность интервала до резкого увеличения ОСК и периода повышенного кровоснабжения молочной железы. Определяли среднее и максимальное значения ОСК и ее увеличение относительно исходных показателей в течение доения. По параметрам кровоснабжения вымени оценивали интенсивность сократительной реакции альвеолярного комплекса. По продолжительности интервала от начала раздражения вымени до момента резкого увеличения кровоснабжения определяли латентный период молокоотдачи. Установлено, что величина разового удоя влияет на параметры молоковыведения и кровоснабжения вымени. Повышение разового удоя привело к сокращению периода выведения первой порции молока $(\mathrm{p}<0,001)$, увеличению средней $(\mathrm{p}<0,001)$ и максимальной $(\mathrm{p}<0,001)$ интенсивности молоковыведения, а также периода машинного доения $(\mathrm{p}<\mathbf{0 , 0 0 1})$. Выведение повышенного количества молока также сопровождалось усилением кровоснабжения вымени, заключавшимся в сокращении периода до резкого повышения ОСК $($ p $<0,05)$, увеличении средней $(p<0,05)$ и максимальной $(\mathrm{p}<0,05)$ ОСК за период доения, а также периода повышенного кровоснабжения вымени $($ р $<0,001)$. Усиление кровоснабжения вымени в опытный период было следствием повышения сократительной реакции миоэпителия и альвеол. Интенсификация процесса сокращения альвеол характеризуется уменьшением латентного периода молокоотдачи, увеличением амплитуды и продолжительности сокращения альвеол. Регуляция процесса молокоотдачи и молоковыведения осуществляется с помощью симпатической нервной системы. Вероятно, тонус симпатической нервной системы вымени изменяется в зависимости от количества накопленного молока. Тонус вымени при молокоотдаче определяет как сократительную реакцию альвеолярного комплекса, так и интенсивность перемещения молока по системе молочных протоков и его выведения через сосок. Повышенный тонус вымени при низкой заполненности молоком приводит к задержке молокоотдачи и выведения первой порции молока, низкой интенсивности сократительной реакции альвеолярного комплекса и молоковыведения. При повышении количества молока в вымени его тонус снижается, обеспечивая сокращение латентного периода молокоотдачи и выведения первой порции молока, усиление сократительной реакции альвеол и повышение интенсивности молоковыведения. Для характеристики изменения тонуса симпатической нервной системы молочной железы предлагается использовать величину латентного периода выведения первой порции молока.

Ключевые слова: коровы, разовый удой, показатели молоковыведения, кровоснабжение вымени, молокоотдача, молочная железа, симпатический тонус, альвеолярный комплекс, сократительная активность.

У молочной железы различают секреторную и двигательную функции. 
Контроль функциональной активности вымени у коров осуществляет симпатическая нервная система (1). В регуляции секреторной функции важную роль играют гормоны пролактин (2) и серотонин (3). Локальный механизм регуляции секреторной функции проявляется в начале лактации при повышении кратности доения одной из половин вымени $(4,5)$. Процесс образования молока в альвеолах происходит непрерывно. Для поддержания высокой секреторной активности молочной железы коров следует своевременно выдаивать (6). В условиях традиционного машинного доения сохраняется относительно постоянный интервал между доениями. Более частое доение на автоматизированных установках приводит к изменению состава молока (7). Выявлена положительная генетическая корреляция частоты доения на автоматизированных установках с показателями молочной продуктивности коров (8).

Двигательная функция вымени реализуется при молокоотдаче, которая заключается в быстром выходе альвеолярного молока в молочные протоки, ходы и цистерны под влиянием сокращающихся миоэпителиальных клеток, активном перемещении секрета по системе молочных протоков и ходов и выведении его из вымени. Для характеристики интенсивности молокоотдачи используют показатели внутривыменного давления (ВВД) $(9,10)$, а также параметры молоковыведения в условиях как традиционного (11-13), так и автоматизированного доения (14). На параметры ВВД и молоковыведения влияет величина разового удоя коров. Выявлена положительная корреляция величины удоя с длительностью машинного доения (13) и интенсивностью молоковыведения $(11,13)$. Установлено увеличение показателей интенсивности и продолжительности доения при возрастании величины разового удоя $(12,15)$. Обнаружена положительная взаимосвязь между величиной ВВД и количеством выдоенного молока из каждой четверти вымени (9), а также показано, что при повышении наполняемости вымени увеличивается максимальная величина ВВД при молокоотдаче (10).

Изучены механизмы, регулирующие интенсивность перемещения молока по системе протоков молочной железы. Установлено снижение сократительной реакции мышц сфинктера соска коров при ручной стимуляции вымени и высказано предположение, что изменение тонуса симпатической нервной системы молочной железы играет роль в процессе выведения молока (16). Эта гипотеза подтверждена экспериментально: $\alpha$ - и $\beta$-адренорецепторы были обнаружены в соске (17-20) и крупных молочных протоках вымени коров $(19,20)$. Выведение молока из молочной железы регулируется симпатической нервной системой через влияние на адренорецепторы гладких мышц молочных протоков, ходов, цистерны вымени и соска. Стимуляция $\alpha$-адренорецепторов вымени вызывает сокращение соска (17), выводных протоков молочной железы (21), торможение процесса молоковыведения (22) и приводит к снижению максимальной интенсивности молоковыведения при доении $(21,23)$. Блокада $\alpha$-адренорецепторов вымени с помощью празозина предотвращает сокращение соска и вызывает релаксацию мышц его сфинктера (24). В ответ на введение $\beta$-адреномиметиков у коров происходит релаксация мышц сфинктера соска (17) и повышение интенсивности молоковыведения в процессе машинного доения $(21,23)$. Предполагается, что гладкие мышцы крупных молочных протоков вымени оказывают большее влияние на интенсивность молоковыведения, чем мышцы соска и его сфинктера $(21,23)$. Индивидуальная способность коров к молокоотдаче обусловлена соотношением $\alpha$ - и $\beta$-адренорецепторов в соске (18). В паренхиме молочной железы обнаружены очень небольшие 
концентрации адренорецепторов, поэтому вероятность влияния симпатической адренергической системы на альвеолярный комплекс низка (19, 20). С помощью параметров ВВД и молоковыведения можно определить характер молокоотдачи в ее начальной стадии, но нельзя объективно оценить интенсивность сократительной реакции миоэпителия и альвеол.

Ранее мы выявили тесную взаимосвязь основных параметров молоковыведения со степенью кровоснабжения вымени перед доением (25) и динамикой его кровоснабжения в период машинного доения (26). Предполагается (27), что повышение кровоснабжения молочной железы в процессе доения вызвано изменением тонуса кровеносных сосудов органа вследствие сжатия и расширения альвеол. Параметры кровоснабжения вымени, регистрируемые при молокоотдаче, отражают активность сократительной реакции альвеол.

В настоящей работе установлено, что выведение повышенного количества молока сопровождается изменением показателей кровоснабжения вымени, вызванным повышением сократительной реакции альвеолярного комплекса.

Нашей целью была оценка механизма сократительной реакции альвеолярного комплекса и молоковыведения у коров при повышении величины разового удоя.

Методика. Исследование проводили методом периодов на 9 коровах (Bos taurus taurus) черно-пестрой породы 2-5-го отелов в первую половину лактации (Всероссийский НИИ физиологии, биохимии и питания сельскохозяйственных животных, Калужская обл.). На каждой корове в контроле и опыте было проведено по 7 наблюдений. В контрольный период разовый удой коров колебался от 3,4 до 6,7 кг, в опытный период его величина превышала контроль на 24,5 \% (p < 0,001), что достигалось посредством изменения периода между доениями.

Доение осуществляли доильным аппаратом АДУ-1, перед началом доения в течение 10 с проводили влажную гигиеническую обработку сосков, после которой сразу подключали доильный аппарат. Параметры молоковыведения регистрировали с помощью ковшового счетчика-датчика (Латвия). По записи процесса выведения молока рассчитывали параметры молоковыведения (11).

Объемную скорость кровотока (ОСК) в вымени оценивали методом электромагнитной флоуметрии. Датчик кровотока («Nihon Kohden», Япония) накладывали на наружную срамную артерию вымени. До начала доения в течение 3 мин регистрировали средние значения ОСК (исходный период), затем проводили запись ОСК на протяжении доения. На кривой ОСК отмечали точки, характеризующие изменение кровоснабжения вымени: начала раздражения молочной железы, моментов резкого увеличения кровоснабжения и достижения его максимума, а также возвращения значений ОСК к исходным показателям. Рассчитывали длительность интервала до резкого увеличения ОСК и периода повышенного кровоснабжения молочной железы. Определяли среднее и максимальное значения ОСК и ее увеличение относительно исходных показателей в течение доения.

Параметры кровоснабжения вымени использовали для оценки интенсивности сократительной реакции альвеолярного комплекса. По продолжительности интервала от начала раздражения вымени до момента резкого увеличения кровоснабжения определяли латентный период молокоотдачи (27). Длительность интервала повышенного кровоснабжения вымени соответствовала периоду сократительной реакции альвеол. Увеличение ОСК за период доения характеризовало величину амплитуды сжатия 
Статистическую обработку данных, корреляционный и регрессионный анализы проводили в программе Microsoft Excel. Определяли средние значения $(M)$ и стандартные ошибки средних $( \pm \mathrm{SEM})$. Достоверность различий оценивали, используя $t$-критерий Стьюдента.

Результаты. Увеличение разового удоя приводило к изменению параметров моловыведения (табл. 1). В опыте было установлено сокращение периода выведения первой порции молока, увеличение средней и максимальной интенсивности молоковыведения.

1. Параметры молоковыведения у коров (Bos taurus taurus) черно-пестрой породы 2-5-го отелов в первую половину лактации в зависимости от разового удоя $(n=9, M \pm \mathrm{SEM}$, Всероссийский НИИ физиологии, биохимии и питания сельскохозяйственных животных, Калужская обл.)

\begin{tabular}{|c|c|c|}
\hline \multirow{2}{*}{ Показатель } & \multicolumn{2}{|c|}{ Период } \\
\hline & контроль & опыт \\
\hline Разовый удой, кГ & $5,11 \pm 0,12$ & $6,36 \pm 0,15^{*}$ \\
\hline Машинный удой, кг & $4,51 \pm 0,13$ & $5,77 \pm 0,16^{*}$ \\
\hline Машинный додой, кг & $0,61 \pm 0,03$ & $0,58 \pm 0,03$ \\
\hline \multicolumn{3}{|l|}{ Интенсивность молоковыведения, кг/мин: } \\
\hline средняя & $1,19 \pm 0,04$ & $1,38 \pm 0,04^{*}$ \\
\hline максимальная & $2,23 \pm 0,05$ & $2,52 \pm 0,05^{*}$ \\
\hline Выдоенность за первые 2 мин доения, \% & $65,1 \pm 2,5$ & $62,6 \pm 2,4$ \\
\hline Латентный период выведения первой порции молока, с & $12,3 \pm 0,8$ & $7,8 \pm 0,7^{*}$ \\
\hline \multicolumn{3}{|l|}{ Продолжительность, с: } \\
\hline доения (общая) & $265,7 \pm 6,4$ & $283,0 \pm 6,8$ \\
\hline машинного доения & $186,3 \pm 5,0$ & $207,0 \pm 5,6^{*}$ \\
\hline машинного додаивания & $79,4 \pm 2,8$ & $76,0 \pm 2,9$ \\
\hline $\begin{array}{l}\text { П р и м е ч а н и е. Описание контрольного и опытного } \\
\text { * Различия с контрольным периодом статистически зн }\end{array}$ & $\begin{array}{l}\text { см. в разде } \\
\text { p }<0,001\end{array}$ & \\
\hline
\end{tabular}

Повышение разового удоя приводило к увеличению машинного удоя, продолжительности машинного доения и вызвало четкую тенденцию к удлинению всего периода доения. Мы не выявили влияния повышения удоя на величину машинного додоя, продолжительность додаивания и показатель выдоенности за первые 2 мин доения. В опытный период была установлена высокая степень взаимосвязи $(r=-0,73 ; \mathrm{p}<0,05)$ и рассчитано уравнение линейной регрессии между величиной разового удоя и продолжительностью периода выведения первой порции молока (рис., А).

Уравнение регрессии свидетельствовало о том, что при увеличении разового удоя у коров сокращался латентный период выведения фракции цистернального молока. Сокращение периода выведения первой порции молока, увеличение средней и максимальной интенсивности молоковыведения при выведении повышенного количества молока указывали на ускорение и повышение интенсивности молокоотдачи.

Отмеченное нами усиление интенсивности молоковыведения в опытный период согласуется с данными R.M. Bruckmaier с соавт. (10), которые при более наполненном вымени в процессе машинного доения установили увеличение количества выдоенного молока и выявили более продолжительный и интенсивный характер молоковыведения. Также показано, что стимуляция $\beta$-адренорецепторов вымени коров вызывает повышение удоя, максимальной интенсивности молоковыведения при машинном доении (21) и увеличение объема молока и скорости его выведения через катетер (17). При стимуляции $\alpha$-адренорецепторов молочной железы наблюдалось снижение удоя и максимальной интенсивности молоковыведения (23). Блокада $\alpha$-адренорецепторов вымени способствовала усилению процесса молоковыведения (24).

Установлено (17), что при снижении тонуса симпатической адрен- 
ергической нервной системы молочной железы наступает релаксация соска, способствующая ускорению выведения молока из вымени. Непосредственно от состояния тонуса сфинктера соска зависит такой показатель, как продолжительность периода выведения первой порции молока. В нашем эксперименте выведение повышенного количества молока сопровождалось снижением длительности этого периода $(\mathrm{p}<0,001)$. Сокращение интервала выведения цистернальной порции молока в опытный период свидетельствовало о снижении тонуса сфинктера соска, а значит, и симпатической нервной системы вымени.

Очевидно, что от количества молока, накопленного в вымени перед доением, зависит симпатический тонус молочной железы. При наличии в ней небольшого количества молока симпатический тонус перед доением повышен. Выдаивание коров в этом случае сопровождается низкой интенсивностью перемещения молока по системе протоков и выведения его через сосок. Увеличение количества молока в емкостной системе железы способствует снижению ее тонуса и таким образом обеспечивает ускорение процесса выведения молока.

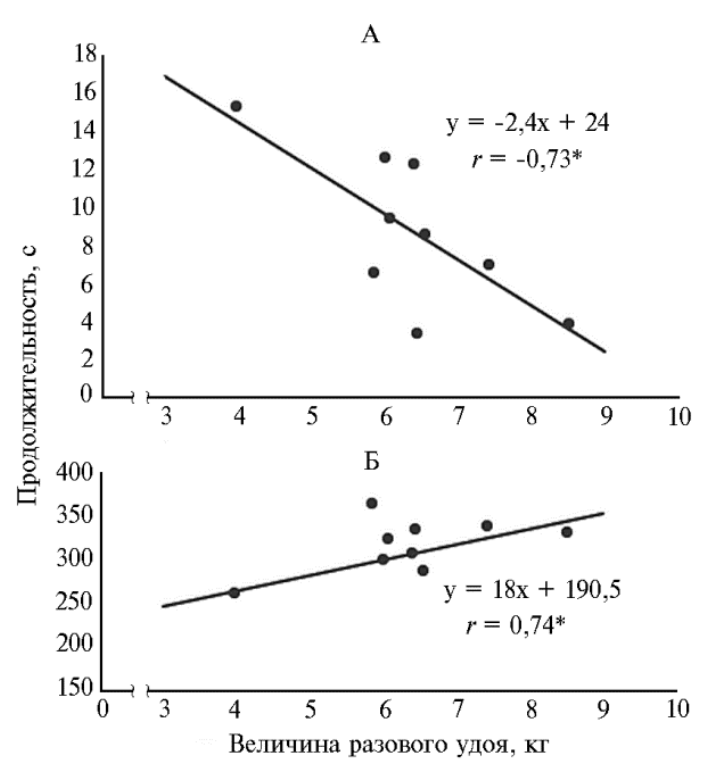

Взаимосвязь между продолжительностью выведения первой порции молока (А), продолжительностью повышенного кровоснабжения вымени (Б) и величиной разового удоя у коров (Bos taurus taurus) черно-пестрой породы 2-5-го отелов в первую половину лактации $(n=9$, Всероссийский НИИ физиологии, биохимии и питания сельскохозяйственных животных, Калужская обл.).

* Статистически значимо при $\mathrm{p}<0,05$.
От интенсивности молоковыведения зависит продолжительность доения. Если бы в опыте тонус вымени не изменился и интенсивность молоковыведения осталась без изменения, то продолжительность доения увеличилась бы на 24,5 \%, как и величина разового удоя. Однако вследствие снижения тонуса вымени и повышения интенсивности молоковыведения в опытный период общая продолжительность доения увеличивалась только на $6,5 \%$. Учитывая функциональную зависимость интенсивности молоковыведения от тонуса молочной железы, продолжительность доения следует считать функцией интенсивности молоковыведения.

Выведение повышенного количества молока вызвало усиление кровоснабжения вымени по сравнению с контро-

лем (табл. 2). В опытный период резкое повышение ОСК в вымени начиналось раньше и продолжалось дольше, чем в контроле. Средняя и максимальная ОСК, а также их увеличение относительно исходных значений за период выдаивания повышенного количества молока превысили аналогичные показатели в контроле.

В опытный период была выявлена тесная положительная связь $(r=0,74 ; \mathrm{p}<0,05)$ между величиной разового удоя и продолжительностью периода повышенного кровоснабжения вымени (см рис., Б). Согласно полученному уравнению регрессии, с увеличением количества молока в 

кровоснабжения вымени.

2. Показатели кровоснабжения вымени коров (Bos taurus taurus) черно-пестрой породы 2-5-го отелов в первую половину лактации в зависимости от разового удоя $(n=9, M \pm \mathrm{SEM}$, Всероссийский НИИ физиологии, биохимии и питания сельскохозяйственных животных, Калужская обл.)

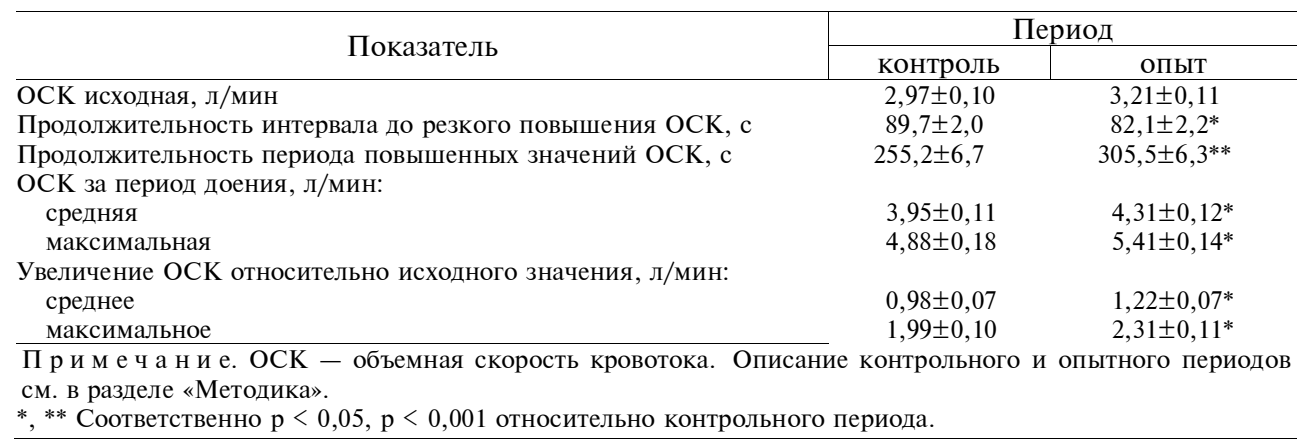

Значения ОСК до начала доения и ее изменения в течение доения в контроле согласуются с данными, полученными нами ранее $(26,27)$. Тенденция к увеличению ОСК до начала доения в опыте была вызвана повышением разового удоя, что подтверждается ранее установленной взаимосвязью между значениями ОСК в половине вымени и величиной разового удоя (25).

Оценка интенсивности сократительной реакции альвеол с помощью параметров кровоснабжения вымени показала, что альвеолярной комплекс вовлечен в регуляцию выведения повышенного количества молока. В опытный период было установлено снижение продолжительности латентного периода молокоотдачи на $8,5 \%(\mathrm{p}<0,05)$ и увеличение длительности периода сократительной реакции альвеол на 19,7 \% (р < 0,001). В контроле значения средней и максимальной амплитуды сжатия альвеолярного комплекса составили соответственно 0,98 $\pm 0,07$ и $1,99 \pm 0,10$ усл. ед. Возрастание разового удоя в опыте вызвало увеличение средней амплитуды сжатия альвеол на $24,5 \%$ ( $<<0,05)$, максимальной - на 16,1\% ( $<0,05)$. Сокращение латентного периода молокоотдачи, повышение амплитуды и продолжительности сокращения альвеол в опыте свидетельствуют о повышении общей сократительной реакции альвеолярного комплекса. Повышение сократительной реакции альвеол наступало в ответ на снижение тонуса симпатической нервной системы вымени при накоплении в нем большего количества молока.

Установленное ранее (10) сокращение латентного периода молокоотдачи, интервала достижения максимального ВВД, повышение максимальной величины ВВД при молокоотдаче при увеличении интервала между доениями может свидетельствовать об усилении молокоотдачи. По мнению авторов, чем меньше заполнение альвеол молоком, тем больше времени требуется миоэпителиальным клеткам для эффективного перемещения альвеолярного молока через систему протоков молочной железы. Считается, что симпатическая нервная система влияет на процесс выведения молока не через регуляцию молокоотдачи, а посредством стимуляции и торможения адренорецепторов, расположенных в районе крупных протоков и цистерн молочной железы (20).

В связи с низкой концентрацией адренорецепторов в паренхиме вымени $(19,20)$ симпатическая нервная система не может оказывать прямого влияния на миоэпителиальные клетки. Их сократительная активность 
регулируется с помощью окситоцина, выход которого из нейрогипофиза также контролируется симпатической нервной системой. Установленное нами сокращение латентного периода молокоотдачи, повышение амплитуды и продолжительности сокращения альвеол в опыте указывало на возможное участие в этом процессе окситоцина. Одним из механизмов регуляции сократительной активности альвеолярного комплекса может быть изменение скорости и концентрации выхода окситоцина из нейрогипофиза. При возрастании количества молока в альвеолах при молокоотдаче, вероятно, возрастает скорость выхода и доставки гормона, а также увеличивается его концентрация в крови.

Таким образом, величина разового удоя у коров влияет на параметры молоковыведения и кровоснабжения вымени. Повышение разового удоя на $24,5 \%$ не отразилось на показателе выдоенности за первые 2 мин доения, величине машинного додоя и продолжительности додаивания, но привело к уменьшению длительности выведения первой цистернальной фракции молока, увеличению интенсивности молоковыведения и продолжительности машинного доения. Изменение основных параметров молоковыведения указывало на ускорение и повышение интенсивности этого процесса при выведении повышенного количества молока. Также усиливалось кровоснабжение вымени, что выражалось в уменышении времени до резкого увеличения кровоснабжения вымени, возрастании средней и максимальной объемной скорости кровотока за период доения, увеличении периода повышенного кровоснабжения вымени. Усиление кровоснабжения вымени было следствием повышения сократительной реакции миоэпителия и альвеол. При этом увеличивается амплитуда и продолжительность сокращений альвеол, что сопровождается удлинением латентного периода молокоотдачи. В регуляции молокоотдачи и молоковыведения участвует симпатическая нервная система. Предполагается, что тонус симпатической нервной системы вымени изменяется в зависимости от количества накопленного молока. Тонус вымени при молокоотдаче определяет как сократительную реакцию альвеолярного комплекса, так и интенсивность перемещения молока по системе молочных протоков и выведения его через сосок. Повышенный тонус при слабой заполненности вымени молоком приводит к задержке молокоотдачи и выведения первой порции молока, низкой интенсивности сократительной реакции альвеолярного комплекса и молоковыведения. При повышении количества молока в вымени его тонус снижается, обеспечивая сокращение латентного периода молокоотдачи и выведения первой порции молока, усиление сократительной реакции альвеол и повышение интенсивности молоковыведения. Величина латентного периода выведения первой порции цистернального молока может служить критерием не только функционального состояния сфинктера соска, но и характеристикой изменения тонуса симпатической нервной системы вымени.

\author{
Калужский филиал ФГОУ ВПО Российский \\ государственный аграрный университет \\ РГАУ-МСХА им. К.А. Тимирязева, \\ 248007 Россия, г. Калуга, ул. Вишневского, 27, \\ e-mail: vpmeshcheryakov@mail.ru $\square$
}

Sel'skokhozyaistvennaya biologiya [Agricultural Biology], 2021, V. 56, № 2, pp. 347-355

\title{
ON THE MILK EJECTION MECHANISM IN COWS
} UPON AN INCREASE IN ONE-TIME MILK YIELD

\author{
V.P. Meshcheryakov $\bowtie$
}

Поступила в редакцию 28 июля 2020 года 
Russian State Agrarian University - Moscow Timiryazev Agricultural Academy, Kaluga Branch, 27, ul. Vishnevskogo, Kaluga, 248007 Russia, e-mail vpmeshcheryakov@mail.ru ( $\square$ corresponding author)

ORCID:

Meshcheryakov V.P. orcid.org/0000-0002-0408-9095

The author declares no conflict of interests

Received July 28, 2020

doi: $10.15389 /$ agrobiology.2021.2.347eng

\section{Abstract}

Sympathetic nervous system regulates milk flow through the udder duct system. However, the mechanisms of contraction of the alveoli upon accumulation of different amounts of milk in the udder have not been studied. In the paper, it is found for the first time that the excretion of an increased amount of milk is accompanied by a change in the parameters of the udder blood supply caused by an increase in the contractile response of the alveolar complex. Thus, the goal of the paper is to investigate the contractile reaction of the alveolar complex and lactation in cows with an increased single-milking yield. Nine black-and-white dairy cows of the 2-5th calving were tested, 7 times each, in the first half of lactation (All-Russian Scientific Research Institute of Physiology, Biochemistry and Nutrition of Farm Animals, Kaluga Province). A serial ADU-1 milking machine and a counter sensor (Latvia) were used to record milking parameters. The single-milking yield ranged from 3.4 to $6.7 \mathrm{~kg}$ in the control period and was $24.5 \%$ higher $(p<0.001)$ in the test period. The volumetric blood flow velocity (VBFV) in the udder was assessed by the electromagnetic flowmetry method. A blood flow sensor (Nihon Kohden, Japan) was fixed on the external pudendal artery of the udder. The average VBFV values were recorded for 3 minutes prior to milking (initial period) and in milking. The points characterizing udder blood supply were marked on the VBFV curve, i.e., the beginning of udder irritation, a sharp increase in the blood supply, its maximum and the baseline restoration. The time intervals until a sharp increase in VBFV and an increased blood supply period were calculated. The average and maximum VBFV values and an increase in volumetric blood flow velocity during milking in relation to the initial indicators were determined. The parameters of the udder blood supply were used to assess the contractile response of the alveolar complex. The latent period until milk secretion was determined based on the time from the beginning of udder irritation to a sharp increase in udder blood supply. It was established that the single-milking yield affects the parameters of milking and the udder blood supply. The increased single-milking yield led to a shorter period for removal of the first portion of milk $(\mathrm{p}<0.001)$, an increase in the average intensity $(\mathrm{p}<0.001)$ and maximum intensity $(\mathrm{p}<0.001)$ of milk removal as well as an increase in the machine-milking period $(\mathrm{p}<0.001)$. The increased milk secretion was also accompanied by an increase in the udder blood supply. I.e., the period before the udder VBFV increased sharply shortened $(\mathrm{p}<0.05)$, while the average $(\mathrm{p}<0.05)$ and maximum $(\mathrm{p}<0.05)$ VBFV values during milking, as well as period of intensive blood supply to the udder $(\mathrm{p}<0.001)$ increased. The increased blood flow during the test period resulted from an increased contractile response of the myoepithelium and alveoli. The intensive contraction of the alveoli, with the increased contraction amplitude and duration, leads to a shorter latent period. The milk let-down and secretion are under regulation of the sympathetic nervous system. Probably, the excitation of the udder sympathetic nervous system depends on the amount of accumulated milk. The udder tone during milk ejection determines both the alveoli contraction and the rate of milk movement through the milk ducts and its removal through the nipple. The increased udder tone when low filling with milk resulted in a delayed let-down, delayed first portion of milk, low contractile response of the alveoli, and low milk removal. With an increase in the amount of milk in the udder, its tone decreases, resulting in a shorter latent period and faster removal of the first portion of milk, strengthening the contractile response of the alveoli and increasing the intensity of milk removal. Therefore, the latent period of secretion of the first portion of milk can be proposed to characterize the tone of the udder sympathetic nervous system.

Keywords: cows, single-milking yield, milk removal parameters, udder blood supply, milk ejection, udder sympathetic tone, alveoli, contractile activity.

\section{R E F E R E N C E S}

1. Peeters G., Coussenes R., Sierens G. Physiology of the nerves in the bovine mammary gland. Archives Internationales de Pharmacodynamie et de Therapie, 1949, 79(1): 75-82.

2. Lacasse P., Ollier S., Lollivier V., Boutinaud M. New insights into the importance of prolactin in dairy ruminants. Journal of Dairy Science, 2016, 99(1): 864-874 (doi: 10.3168/jds.2015-10035).

3. Kessler E.C., Wall S.K., Hernandez L.L., Bruckmaier R.M., Gross J.J. Shot communication: Circulating serotonin is related to the metabolic status and lactation performance at the onset of lactation in dairy cows. Journal of Dairy Science, 2018, 101(12): 11455-11460 (doi: 10.3168/jds.2018-14626).

4. Wall E.H., McFadden T.B. The effect of removal or four-times-daily milking on mammary expression of genes involved in the insulin-like growth factor-1 axis. Journal of Dairy Science, 2010, 93(9): 4062-4070 (doi: 10.3168/jds.2010-3162).

5. Murney R., Stelwagen K., Wheeler T.T., Margirison J.K., Singh K. The effect of milking 
frequency in early lactation on milk yield, mammary cell turnover, and secretory activity in grazing dairy cows. Journal of Dairy Science, 2015, 98(1): 305-311 (doi: 10.3168/jds.2014-8745).

6. Davis S.R. TRIENNIAL LACTATION SYMPOSIUM/BOLFA: Mammary growth during pregnancy and lactation and its relationship with milk yield. Journal of Animal Science, 2017, 95(12): 5675-5688 (doi: $10.2527 /$ jas2017.1733).

7. Løvendahl P., Chagunda G.G. Covariance among milking frequency, milk yield, and milk composition from automatically milked cows. Journal of Dairy Science, 2011, 94(11): 5381-5392 (doi: 10.3168/jds.2010-3589).

8. Nixon M., Bohmanova J., Jamrozik J., Schaeffer L.R., Hand K., Miglior F. Genetic parameters of milking frequency and milk production traits in Canadian Holsteins milked by an automated milking system. Journal of Dairy Science, 2009, 92(7): 3422-3430 (doi: 10.3168/jds.2008-1689).

9. Graf G.C., Lawson D.M. Factors affecting intramammary pressure. Journal of Dairy Science, 1968, 51(10): 1672-1675 (doi: 10.3168/jds.S0022-0302(68)87250-9).

10. Bruckmaier R.M., Hilger M. Milk ejection in dairy cows at different degrees of udder filling. Journal of Dairy Research, 2001, 68(3): 369-376 (doi: 10.1017/S0022029901005015).

11. Kokorina E.P. Uslovnye refleksy i produktivnost' zhivotnykh [Conditioned reflexes and animal productivity]. Moscow, 1986 (in Russ.).

12. Tancin V., Ipema B., Hogewerf P., Mačuhová I. Sources of variation in milk flow characteristics at udder and quarter levels. Journal of Dairy Science, 2006, 89(3): 978-988 (doi: 10.3168/jds.S0022-0302(06)72163-4).

13. Göft H., Duda J., Dethlefsen A., Worstorff H. Untersuchungen zur zuchterischen Verwendung der Melkbarkeit beim Rind unter Berucksichtigung von Milchflußkurven. Zuchtungskunde, 1994, 66(1): 23-37.

14. Juozaitiene V., Juozaitis A., Zymantiene J., Spancerniene U., Antanaitis R., Zilaitis V., Tusas S., Yilmaz A. Evaluation of automatic milking system variables in dairy cows with different levels of lactation stage and reproduction states. Journal of Dairy Research, 2019, 86(4): 410-415 (doi: $10.1017 /$ S0022029919000670).

15. Sandrucci A., Tamburini A., Bava L., Zucali M. Factors affecting milk flow traits in dairy cows: Results of a field study. Journal of Dairy Science, 2007, 90 (3): 1159-1167 (doi: 10.3168/jds.S00220302(07)71602-8).

16. Lefcourt A.M. Effect of teat stimulation on sympathetic tone in bovine mammary gland. Journal of Dairy Science, 1982, 65(12): 2317-2322 (doi: 10.3168/jds.S0022-0302(82)82503-4).

17. Bernabé J., Peeters G. Studies on the motility of smooth muscles of the teats in lactating cows. Journal of Dairy Research, 1980, 47(3): 259-275 (doi: 10.1017/S0022029900021154).

18. Roets E., Vandeputte-Van Messom G., Peeters G. Relationship between milkability and adrenoceptor concentration in teat tissue in primiparous cows. Journal of Dairy Science, 1986, 69(12): 3120-3130 (doi: 10.3168/jds.S0022-0302(86)80776-7).

19. Hammon H.M., Bruckmaier R.M., Honegger U.E., Blum J.W. Distribution and density of $\alpha-$ and $\beta$-adrenergic binding sites in the bovine mammary gland. Journal of Dairy Research, 1994, 61(1): 47-57 (doi: 10.1017/S0022029900028041).

20. Wellnitz O., Zurbriggen A., Friis R.R., Blum J.W., Bruckmaier R.M. $\alpha 1 c-$ and $\beta 2-$ adrenergic receptor mRNA distribution in the bovine mammary gland detected by competitive RT-PCR. Journal of Dairy Research, 2001, 68(4): 699-704 (doi: 10.1017/S0022029901005076).

21. Inderwies T., Riedl J., Kiossis E., Brickmaier R.M. Effects of $\alpha$ - and $\beta$-adrenergic receptor stimulation and oxytocin receptor blockade on milking characteristics in dairy cows before and after removal of the teat sphincter. Journal of Dairy Research, 2003, 70(3): 289-292 (doi: $10.1017 /$ S0022029903006289).

22. Markov A.G., Mil'ke G. Sel'skokhozyaistvennaya biologiya, 1989, 24(2): 127-129 (in Russ.).

23. Inderwies T., Pfaffl M.W., Bruckmaier R.M. Milking characteristics and their relation to adrenergic receptor mRNA expression and ligand binding in the mammary gland of dairy cows. Domestic Animal Endocrinology, 2003, 25(3): 275-286 (doi: 10.1016/S0739-7240(03)00059-6).

24. Vandeputte-Van Messom G., Bernabe J., Burvenich C., Peeters G. Effect of prazozin on the function of the teat sphincter in lactating cows. Journal of Dairy Research, 1984, 51(2): 219-226 (doi: 10.1017/S0022029900023475).

25. Meshcheryakov V.P., Shevelev N.S. About intensity of blood supply of cow udder before milking and parameters of milking. Sel'skokhozyaistvennaya biologiya, 2010, 4: 124-126 (in Russ.).

26. Shevelev N.S., Meshcheryakov V.P. Correlation between dynamics of milk discharge and circulation of the blood in cow udder during milking. Sel'skokhozyaistvennaya biologiya, 2008, 4: 8085 (in Russ.).

27. Meshcheryakov V.P. Izvestiya TSKHA, 2013, 3: 89-101 (in Russ.). 